\title{
Efeito de inibidores da peroxidase sobre a conservação de raízes de mandioca in natura
}

Effect of peroxidase inhibitors on the conservation of fresh cassava roots

\section{Autores | Authors}

\ Paula Acácia Silva RAMOS

Universidade Federal de Viçosa (UFV) Departamento de Fitotecnia Av. P.H. Rolfs, $s / n$ CEP: 36570-000

Viçosa/MG - Brasil

e-mail: paula_agro_ramos@yahoo.com.br

Tocio SEDIYAMA

Universidade Federal de Viçosa (UFV) Departamento de Fitotecnia Viçosa/MG - Brasil e-mail: t.sediyama@ufv.br

Anselmo Eloy Silveira VIANA

Universidade Estadual do Sudoeste da Bahia (UESB)

Departamento de Fitotecnia e Zootecnia Vitória da Conquista/BA - Brasil e-mail: ae-viana@uol.com.br

\section{Danilo Manuel PEREIRA} Fernando Luiz FINGER

Universidade Federal de Viçosa (UFV) Departamento de Fitotecnia Viçosa/MG - Brasil e-mail: danilopereira_agrn@yahoo.com.br ffinger@ufv.br

Autor Correspondente / Corresponding Author

Recebido / Received: 23/04/2012 Aprovado / Approved: 08/05/2013 Publicado / Published: jun./2013

\section{Resumo}

A alta perecibilidade da mandioca (Manihot esculenta, Crantz) in natura faz com que o consumo seja feito dentro de um período curto após a colheita. A principal causa de perda se deve à deterioração fisiológica, atribuída à atividade da enzima peroxidase (E.C.1.11.1.7). Este trabalho objetivou avaliar o efeito combinado de diferentes inibidores da peroxidase nas concentrações de 1, 5 e 10 mM em raízes da variedade Cacau Amarela. As raízes foram tratadas por uma hora em soluções com ácido ascórbico, bissulfito de sódio, sódio, $\mathrm{Na}_{2}$-EDTA, L-cisteína e SDS, e armazenadas a $25^{\circ} \mathrm{C}$ por seis dias. A cada dois dias, foram realizadas análises visuais e retiradas amostras para posterior avaliação da peroxidase. Todos os tratamentos foram eficientes em aumentar a vida de prateleira das raízes de mandioca in natura em até quatro dias. O tratamento com ácido ascórbico e bissulfito de sódio a $10 \mathrm{mM}$ e L-cisteína a $5 \mathrm{mM}$ foram eficientes em aumentar a vida de prateleira em até seis dias. No segundo dia de armazenamento, houve redução na atividade da peroxidase em relação ao controle, em todas as concentrações dos inibidores aplicados.

Palavras-chave: Escurecimento enzimático; Peroxidase; Longevidade; Vida de prateleira.

\section{Summary}

The high perishability of fresh cassava (Manihot esculenta, Crantz) means it must be consumed in a very short period after harvesting. The main cause of loss is due to the physiological deterioration attributed to the action of peroxidase (EC1.11.1.7). This work aimed to evaluate the combined effect of different peroxidase inhibitors at concentrations of 1,5 and $10 \mathrm{mM}$ on the peroxidase activity of roots of the Cacau Amarela cassava variety. The roots were immersed for one hour in solutions containing ascorbic acid, sodium bisulphite, $\mathrm{Na}_{2}$-EDTA, sodium dodecyl sulphate (SDS) and L-cysteine. After drying, the roots were stored at $25^{\circ} \mathrm{C}$ for six days. The visual appearance was analyzed every two days and samples removed for the subsequent evaluation of peroxidase. All the treatments were effective in increasing the shelf life of the fresh cassava roots by up to four days. The treatments with ascorbic acid, bisulphite and L-cysteine were efficient in increasing the shelf life by up to 6 days at concentrations of $10 \mathrm{mM}, 10 \mathrm{mM}$ and $5 \mathrm{mM}$, respectively. For all the inhibitors at all the concentrations applied there was a decrease in peroxidase activity on the second day of storage as compared to the control.

Key words: Enzymatic browning; Peroxidase; Longevity; Longer shelf life. 


\section{Introdução}

No Brasil, a mandioca é uma importante fonte de matéria-prima rica em amido. É consumida principalmente como raíz in natura, processada e produtos derivados, como farinha e polvilho (OLIVEIRA e PANTAROTO, 2003).

A dificuldade em manter raízes frescas por alguns dias após a colheita, é um dos maiores problemas da comercialização in natura e de raízes processadas. Estas tuberosas são susceptíveis a diversos estresses, como danos mecânicos causados pela colheita, pelo transporte e pelo armazenamento (CEREDA e VILPOUX, 2003). Um dos principais desafios da comercialização in natura e do processamento é o rápido escurecimento da polpa, em razão da produção de polímeros de coloração marrom (melaninas) oriundos de reações catalisadas por enzimas, como a peroxidase (POD, E.C. 1.11.1.7.) e a polifenoloxidase (PPO)(TOMÁS-BARBERÁN e SPÍN, 2001; VILAS BOAS, 2002). Silva et al. (2009) demonstraram que a POD afeta negativamente a cor dos produtos minimamente processados.

O processo de deterioração fisiológica, que limita o armazenamento das raízes, se inicia nas primeiras 48 horas depois da colheita. Este processo resulta na formação de estrias azuladas, descoloração vascular e escurecimento dos tecidos ao longo do parênquima de armazenamento. Assim, raízes de mandioca recémcolhidas perdem em qualidade e quantidade, resultando em um produto com aparência indesejável ao consumidor (ARAÚJO, 1999), o que limita sua oferta nos centros urbanos distantes das regiões produtoras (BORGES et al., 2002).

Alguns fatores aumentam o processo do escurecimento enzimático em raízes de mandioca in natura, como a disponibilidade de oxigênio ao tecido, a perda de água, a oxidação de compostos fenólicos e a elevação da atividade enzimática de fenilalanina amonioliase, polifenoloxidase e peroxidase (SILLANPAA et al., 2001). Uma das alternativas para evitar esta deterioração é o uso de variedades resistentes. Entretanto, até o momento este material não foi desenvolvido. Assim, a opção mais acessível é o emprego de técnicas de conservação in natura de raízes frescas (KATO, 1988; BORGES et al., 2002).

Em razão da inexistência na literatura de relatos da utilização de inibidores para prevenir o escurecimento, este trabalho teve como objetivo avaliar o efeito de diferentes inibidores da peroxidase, visando a reduzir o escurecimento enzimático e prolongar a qualidade pós-colheita das raízes de mandioca in natura da variedade Cacau Amarela.

\section{Material e métodos}

\subsection{Matéria-prima}

A variedade de mandioca (Manihot esculenta) utilizada foi a Cacau Amarela da região da Zona da Mata de Minas Gerais. As raízes foram colhidas aos 12 meses após o plantio, em Viçosa-MG.

\subsection{Tratamentos com inibidores da POD}

As raízes isentas de doenças e danos aparentes foram selecionadas e lavadas em água corrente. Em uma das extremidades (parte que liga a raiz ao caule), foi realizado um corte de $1 \mathrm{~cm}$ visando ao aumento da embebição dos tratamentos. Em seguida, as raízes foram separadas e colocadas para embeber por uma hora em soluções contendo inibidores da POD, nas concentrações de $1 \mathrm{mM}, 5 \mathrm{mM}$ e $10 \mathrm{mM}$, quais sejam: ácido ascórbico, bissulfito de sódio, sal dissódico do ácido etilenodiaminotetracético ( $\left.\mathrm{Na}_{2} \mathrm{EDTA}\right)$, L-cisteína e dodecil sulfato de sódio (SDS). O controle foi composto por raízes embebidas em água por uma hora.

Após o período da embebição, as raízes já tratadas foram retiradas e secas; em seguida, foram deixadas sob uma bancada por um período de seis dias, a uma temperatura de $25^{\circ} \mathrm{C}$.

\subsection{Análise da qualidade pós-colheita de raízes de mandioca in natura}

Para analisar o escurecimento que se forma na polpa (córtex) de raízes in natura de mandioca, a cada dois dias foram cortados pedaços com $2 \mathrm{~cm}$ de espessura. Dez avaliadores foram recrutados em função da análise sensorial e da análise da qualidade das raízes. Foi realizado um teste com escalas que variaram de acordo com o número de anéis escuros ao longo do córtex das raízes e de acordo com a ausência do sabor amargo. As amostras tratadas foram colocadas numa bancada, codificadas com números aleatórios, pelas quais os avaliadores passavam analisando o aparecimento das estrias ao longo das raízes cortadas.

Para a análise sensorial, o tempo de cocção foi de 25 minutos. Partes dos pedaços cortados foram cozidas e degustadas, e as notas foram dadas junto com as fichas de descrição de pontuação adotada para avaliar o nível de deterioração das raízes. A descrição foi realizada de acordo com os critérios a seguir: (1) sem anel deteriorativo - ponto ideal de consumo, sem sabor amargo; (3) um anel deteriorativo - início de estrias deteriorativas, mas ainda consumível, sem sabor amargo; (5) dois anéis deteriorativos - mudança do sabor quando cozida; (7) mais que três anéis deteriorativos - imprópria para consumo ou cozimento, sabor amargo (Figura 1).

\subsection{Atividade enzimática da POD}

Amostras de $2 \mathrm{~cm}$ de espessura da polpa das raízes tratadas com inibidores da POD foram cortadas a cada dois dias; em seguida, foram embaladas em papel alumínio e congeladas em nitrogênio líquido, sendo 

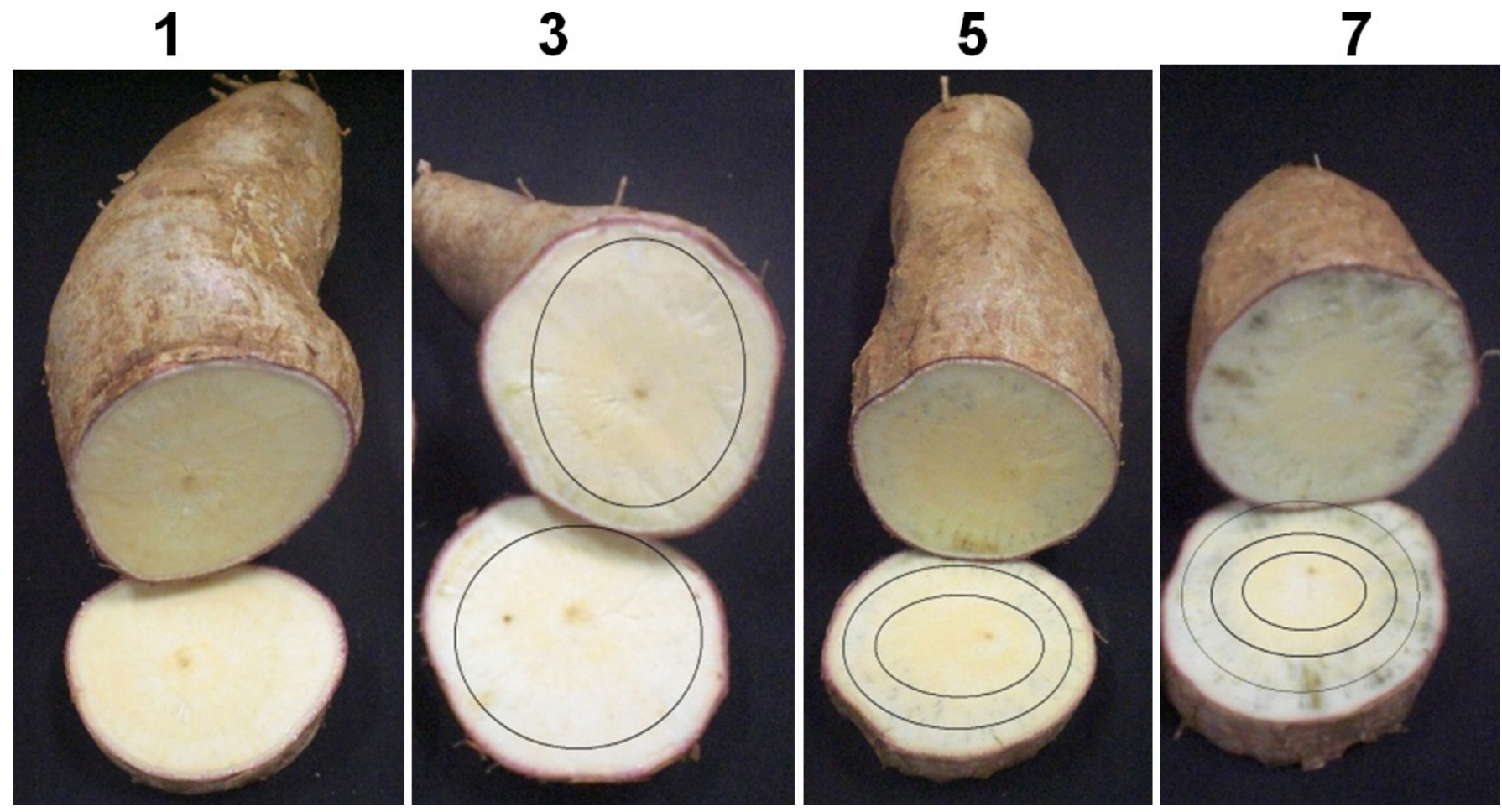

Figura 1. Notas da análise visual da deterioração fisiológica em raízes de mandioca in natura.

posteriormente armazenadas em freezer à temperatura de $-20{ }^{\circ} \mathrm{C}$ até sua utilização.

Pesaram-se $30 \mathrm{~g}$ de raízes, que foram então homogeneizadas em $150 \mathrm{~mL}$ de solução tampão fosfato de potássio $(0,1 \mathrm{M} \mathrm{e} \mathrm{pH} \mathrm{6,5,} \mathrm{bissulfito} \mathrm{de} \mathrm{sódio} \mathrm{a} \mathrm{0,1 \%} \mathrm{e}$ cloreto de sódio a 0,15 M), por três minutos, utilizando-se um politron a $4{ }^{\circ} \mathrm{C}$. Em seguida, esta mistura foi filtrada com quatro camadas de gaze. O filtrado foi recebido no béquer em banho de gelo. Na etapa seguinte, o filtrado foi centrifugado a $11.000 \times \mathrm{g}$ a $4{ }^{\circ} \mathrm{C}$, por 30 minutos. $\mathrm{O}$ sobrenadante foi utilizado nas análises de atividade da POD e de proteína total. Na ausência de inibidores, a atividade relativa da POD foi considerada como $100 \%$ e as demais foram calculadas com base nesta.

A determinação da atividade enzimática foi realizada de acordo com o método descrito por Neves (2003), utilizando-se um espectrofotômetro em unidades de absorbância a $470 \mathrm{~nm}$ a $25^{\circ} \mathrm{C}$. Para a reação, misturou-se em $1,5 \mathrm{~mL}$ do tampão fosfato a $0,1 \mathrm{M}$ e pH 6,5 com 0,5 mL de peróxido de hidrogênio a $1,8 \%, 0,5 \mathrm{~mL}$ do guaiacol a $1,7 \%$ e $0,5 \mathrm{~mL}$ do extrato enzimático concentrado. O volume total da reação foi $3 \mathrm{~mL}$. A alteração na absorbância foi medida ao longo de três minutos.

A atividade enzimática foi expressa em UA min $^{-1}$ $\mathrm{mg}^{-1}$ de proteína. A proteína total do extrato contendo a POD foi determinada segundo a metodologia descrita por Bradford (1976), utilizando-se soro bovino tendo a albumina como proteína padrão.

\subsection{Análise estatística}

O delineamento experimental utilizado foi inteiramente casualizado, seguido do teste Ducan a $5 \%$ de significância, para as concentrações de cada inibidor, com seis tratamentos (inibidores) e quatro repetições (raízes de mandioca). O processamento de dados e a análise estatística foram realizados com emprego do programa SAEG (2007).

Para a análise visual, foi efetuada a média das notas das concentrações em cada dia, representadas em porcentagem: $100 \%$ quando todas as notas foram iguais; $66,66 \%$ quando pelo menos duas notas foram iguais; 33,33\% quando pelo menos uma nota foi diferente.

\section{Resultados e Discussão}

\subsection{Análise da qualidade pós-colheita de raízes de mandioca in natura}

Dois dias após a colheita, 100 \% das raízes tratadas com inibidores de peroxidase nas concentrações de 1, 5 e $10 \mathrm{mM}$, e sem tratamento, permaneceram com nota 1 (Tabela 1). Assim, raízes de mandioca comercializadas de forma in natura podem ser armazenadas por até dois dias, sem o aparecimento do escurecimento enzimático, caracterizado por estrias ao longo do parênquima de armazenamento na polpa das raízes (CHITARRA e PRADO, 2002). 
Efeito de inibidores da peroxidase sobre a conservação de raízes de mandioca in natura

RAMOS, P. A. S. et al.

Tabela 1. Média das notas de classificação quanto à qualidade pós-colheita de raízes de mandioca in natura tratadas ou não com inibidores da POD, nas concentrações: 1 mM (C1), 5 mM (C5) e 10 mM (C10), ao longo de seis dias de armazenamento.

\begin{tabular}{|c|c|c|c|c|c|c|c|c|c|}
\hline \multirow[t]{2}{*}{ Tratamentos } & \multicolumn{3}{|c|}{$\begin{array}{c}2^{\circ} \text { Dia } \\
\text { Concentração }\end{array}$} & \multicolumn{3}{|c|}{$\begin{array}{c}4^{\circ} \text { Dia } \\
\text { Concentração }\end{array}$} & \multicolumn{3}{|c|}{$\begin{array}{c}6^{\circ} \text { Dia } \\
\text { Concentração }\end{array}$} \\
\hline & C1 & C5 & C10 & C1 & C5 & C10 & C1 & C5 & C10 \\
\hline Controle & $100 \%(1)$ & $100 \%(1)$ & $100 \%(1)$ & $100 \%(7)$ & $100 \%(7)$ & $100 \%(7)$ & $100 \%(7)$ & $100 \%(7)$ & $100 \%(7)$ \\
\hline Acido Ascórbico & $100 \%(1)$ & $100 \%(1)$ & $100 \%(1)$ & $33,3 \%(5)$ & $33,3 \%(7)$ & $33,3 \%(1)$ & $66,6 \%(7)$ & $66,6 \%(7)$ & $33,3 \%(3)$ \\
\hline Bissulfito de $\mathrm{Na}$ & $100 \%(1)$ & $100 \%(1)$ & $100 \%(1)$ & $33,3 \%(7)$ & $66,6 \%(1)$ & $66,6 \%(1)$ & $33,3 \%(7)$ & $66,6 \%(3)$ & $66,6 \%(3)$ \\
\hline $\mathrm{Na}_{2}$ EDTA & $100 \%(1)$ & $100 \%(1)$ & $100 \%(1)$ & $100 \%(3)$ & $100 \%(3)$ & $100 \%(3)$ & $100 \%(5)$ & $100 \%(5)$ & $100 \%(5)$ \\
\hline L-cisteína & $100 \%(1)$ & $100 \%(1)$ & $100 \%(1)$ & $100 \%(3)$ & $100 \%(3)$ & $100 \%(3)$ & $66,6 \%(5)$ & $33,3 \%(3)$ & $66,6 \%(5)$ \\
\hline SDS & $100 \%(1)$ & $100 \%(1)$ & $100 \%(1)$ & $33,3 \%(7)$ & $33,3 \%(5)$ & $33,3 \%(3)$ & $33,3 \%(7)$ & $66,6 \%(5)$ & $66,6 \%(5)$ \\
\hline
\end{tabular}

Porcentagem dos valores médios das notas do escurecimento enzimático.

O tratamento com ácido ascórbico na concentração de $10 \mathrm{mM}$ prolongou o período de armazenamento em até seis dias, resultando em $33,3 \%$ de raízes com nota 3 (adequada para consumo) e 66,6 \% com nota 7 (imprópria para consumo), nas concentrações 1 e $5 \mathrm{mM}$ (Tabela 1 e Figura 2). Resultado semelhante foi encontrado no armazenamento de tubérculos de batata e rizomas de taro, com inibição de 100 \% usando-se o ácido ascórbico, nas concentrações de 5 e $10 \mathrm{mM}$, respectivamente (DUANGMAL e APENTEN, 1999).

Dentre os antioxidantes mais utilizados em órgão de armazenamento, destacam-se os ácidos cítrico, ascórbico e eritórbico. O ácido ascórbico também é usado na indústria de batatas minimamente processadas (PINELI et al., 2005), o que demonstra a possível utilização desse tratamento em mandioca para o consumo in natura, como o sugerido neste trabalho, visando a aumentar a conservação de raízes.

A eficiência de tratamentos químicos contendo ácido ascórbico, cloreto de cálcio e cloridrato de L-cisteína na prevenção do escurecimento também foi comprovada por Melo e Vilas Boas (2006), os quais demonstraram que as atividades das enzimas polifenoloxidase (PPO) e peroxidase $(P O D)$ foram afetadas interativamente pelos fatores 'tratamento químico' e 'tempo de armazenamento'. Ambas as enzimas se associam com os processos de escurecimento nos vegetais (REIS et al., 2004).

O escurecimento enzimático em raízes de mandioca in natura foi reduzido com o tratamento utilizando-se o sal bissulfito de sódio nas concentrações 5 e 10 mM, prolongando em até seis dias a vida de prateleira (Figura 3). Das raízes tratadas com esse sal, 66,6\% tiveram nota 3, nas concentrações 5 e $10 \mathrm{mM}$, e 33,3 \% tiveram nota 7 na concentração de $1 \mathrm{mM}$ (imprópria para consumo). A menor concentração não foi suficiente para reduzir o efeito do escurecimento e, como consequência, as raízes apresentaram-se com maior dano deteriorativo (Tabela 1).

Estes resultados demonstram a influência benéfica dos tratamentos aplicados, sugerindo como técnica adicional à limpeza das raízes in natura, a incorporação de soluções com inibidores da POD como agente redutor do escurecimento, uma vez que esta enzima está envolvida em processos de lignificação, o que confere maior proteção ao tecido vegetal (CANTOS et al., 2002).

Das raízes de mandioca in natura tratadas com $\mathrm{Na}_{2-}$ EDTA, $100 \%$ tiveram nota $3 \mathrm{em}$ todas as concentrações no quarto dia de armazenamento, já no sexto dia, $100 \%$ das raízes tiveram nota 5. Assim, evidencia-se a eficiência deste tratamento em prolongar a vida de prateleira e evitar o escurecimento em até quatro dias de armazenamento (Tabela 1 e Figura 4).

A classificação de raízes com nota 5 indica o início da deterioração, em função da mudança no sabor das raízes, o que justifica o sexto dia de armazenamento não ser considerado como melhor resultado deste tratamento. Entretanto, raízes com essa classificação, mesmo não sendo isentas de anéis deteriorativos - o que desqualifica o produto - são comercializadas e podem ser consumidas.

Dentre as substâncias com efeito antioxidante, destaca-se a L-cisteína, que pode atuar como inibidor da síntese ou da ação de enzimas ligadas à oxidação dos polifenóis, ou age como adsorvente dessas substâncias (GOULART et al., 2010), anulando o efeito tóxico de muitas substâncias fenólicas (VIEIRA e FATIBELLO-FILHO, 2005). $O$ mesmo resultado foi verificado neste trabalho com raízes in natura de mandioca (Figura 5) e com batata Ágata minimamente processada (PINELI et al., 2005), em que a L-cisteína se mostrou eficiente em retardar o escurecimento enzimático e prolongou a vida de prateleira das raízes.

O tratamento com L-cisteína a $5 \mathrm{mM}$ foi eficiente em proporcionar maior longevidade das raízes até 0 sexto dia de armazenamento, em que 33,3\% das raízes tratadas tiveram nota 3 , e $66,6 \%$ das raízes tratadas nas concentrações 1 e 10 tiveram nota 5 (Tabela 1). Portanto, o tratamento das raízes de mandioca in natura com esse aminoácido foi eficiente em conservar, em até seis dias de armazenamento, raízes com boa aparência e ideais para consumo (Figura 5). 

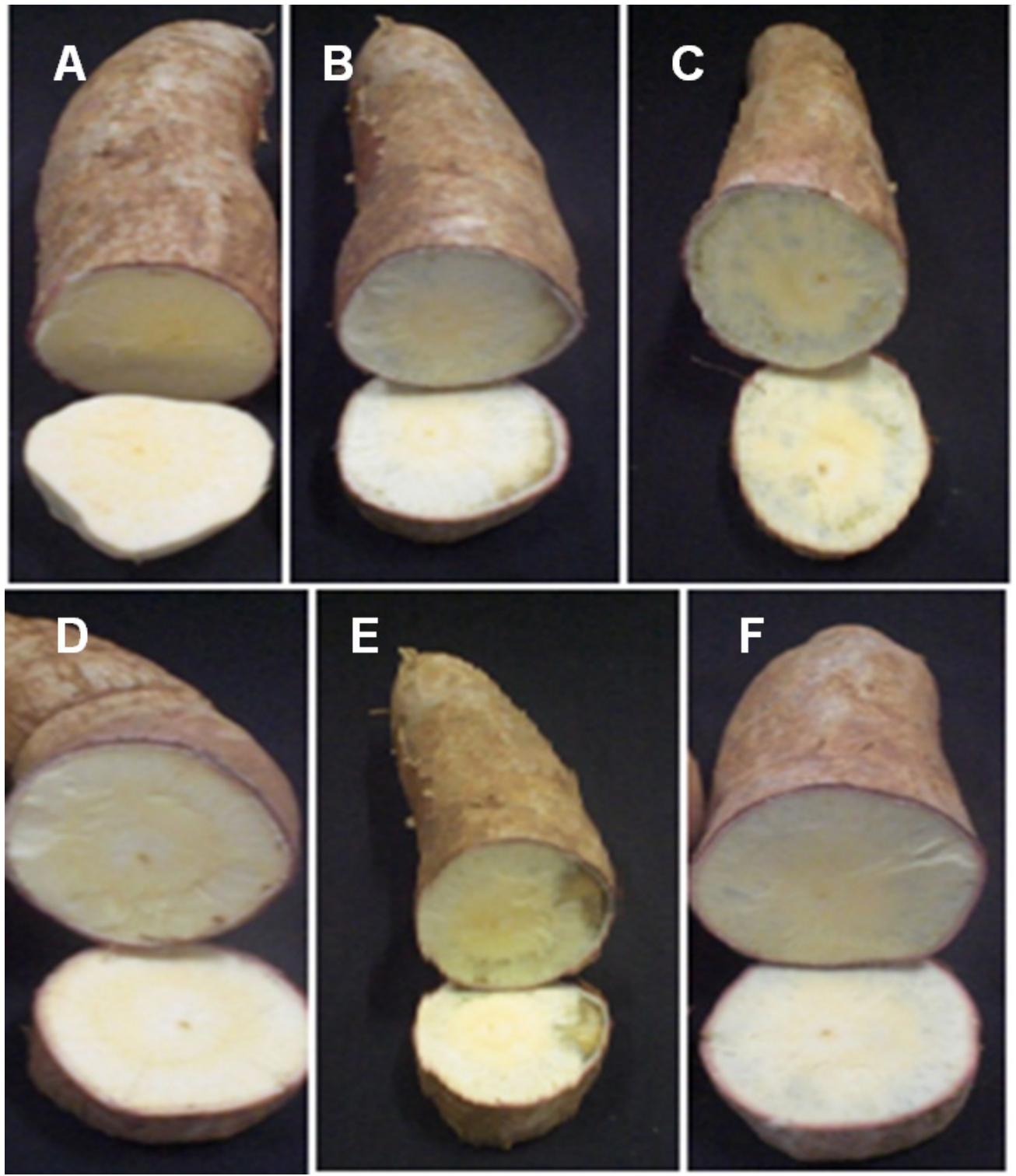

Figura 2. Aparência das raízes de mandioca após os tratamentos com ácido ascórbico: (A) dia 2- concentrações 1, 5 e 10 mM, nota 1; (B) dia 4, concentrações $1 \mathrm{mM}$, nota 5; (C) $5 \mathrm{mM}$, nota 7; (D) $10 \mathrm{mM}$, nota 1; (E) dia 6, concentrações $1 \mathrm{mM}$ e $5 \mathrm{mM}$, nota 7; (F) $10 \mathrm{mM}$, nota 3.
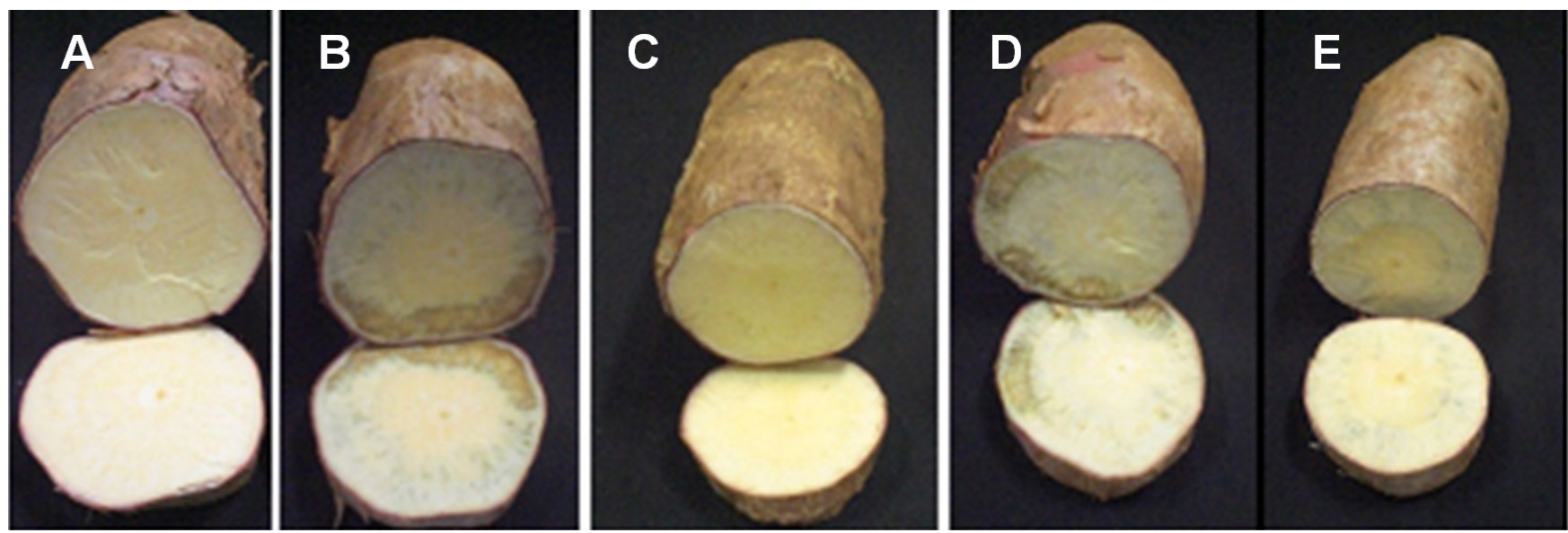

Figura 3. Aparência das raízes de mandioca após os tratamentos com bissulfito de sódio: (A) dia 2- concentrações 1, 5 e 10 $\mathrm{mM}$, nota 1; (B) dia 4- concentração $1 \mathrm{mM}$, nota 7; (C) $5 \mathrm{mM}$ e $10 \mathrm{mM}$, nota 1; (D) dia 6- concentração $1 \mathrm{mM}$, nota 7 ; (E) 5 mM e $10 \mathrm{mM}$, nota 3 . 

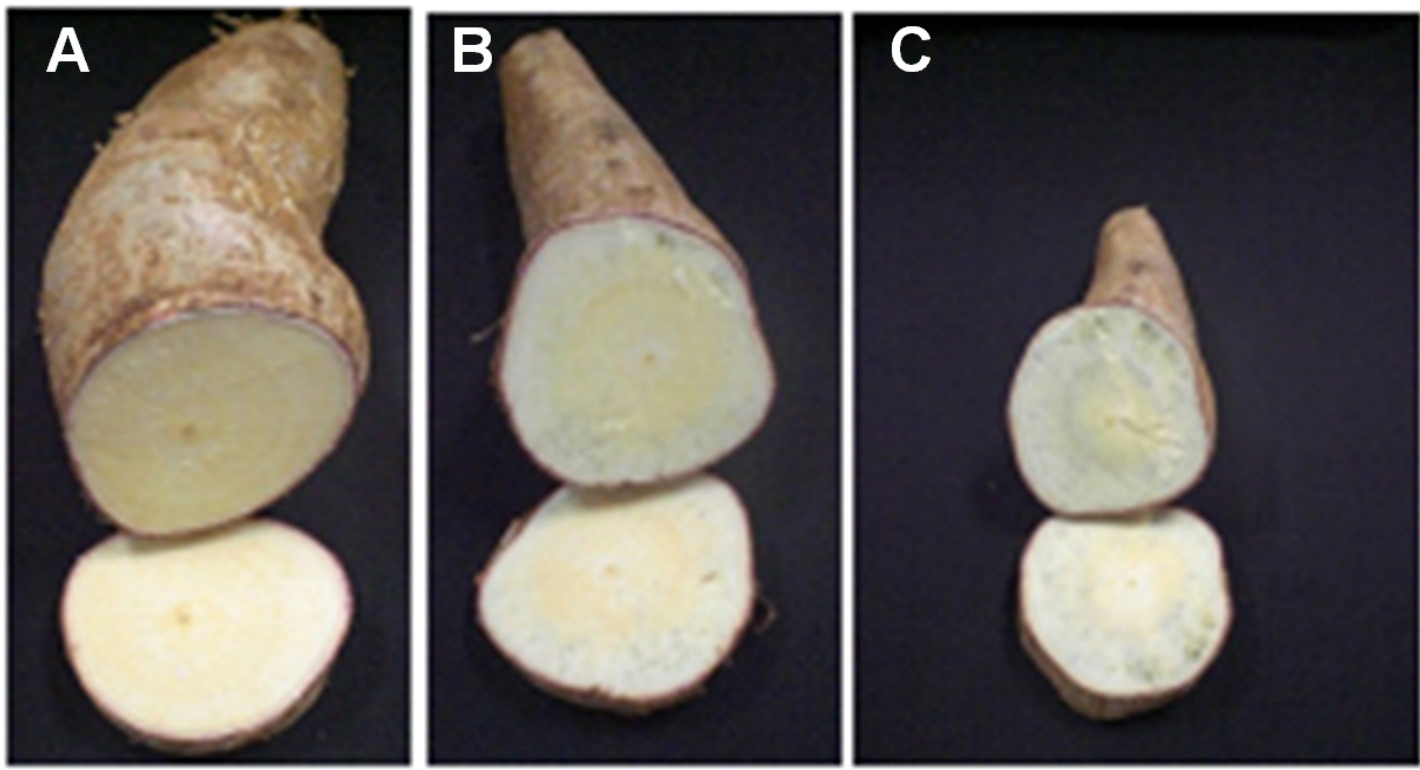

Figura 4. Aparência das raízes de mandioca após os tratamentos com $\mathrm{Na}_{2-}$ EDTA: (A) dia 2- concentrações 1, 5 e 10 mM, nota 1; (B) dia 4- concentrações 1, 5 e $10 \mathrm{mM}$, nota 3; (C) dia 6- concentrações 1, 5 e 10mM, nota 5.
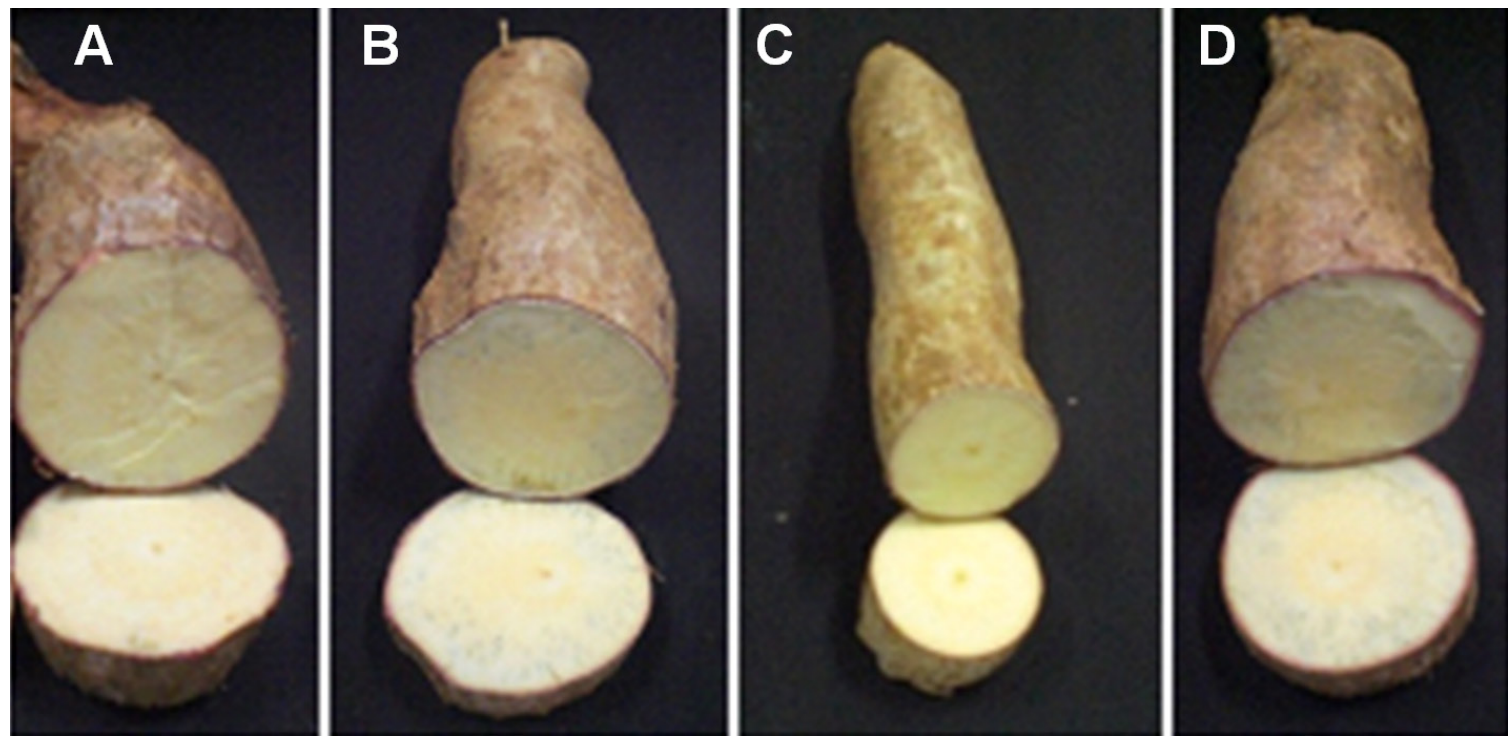

Figura 5. Aparência das raízes de mandioca após os tratamentos com L-cisteína: (A) dia 2- concentrações 1, 5 e 10 mM, nota 1; (B) dia 4- concentrações 1, 5 e 10 mM, nota 3; (C) dia 6- concentração 5 mM, nota 3; (D) 1 mM e 10 mM, nota 5.

O tratamento feito com solução de dodecil sulfato de sódio (SDS) a $10 \mathrm{mM}$ foi eficiente em aumentar o período de armazenamento em até quatro dias, tendo aproximadamente 33,3 \% das raízes in natura em boas condições para comercialização, com nota 3 (Tabela 1 e Figura 6). Entretanto, no sexto dia de avaliação, 66,6 \% das raízes tiveram nota 5 nas concentrações 5 e $10 \mathrm{mM}$, e mesmo não sendo a melhor classificação, é um material utilizado comercialmente.

O SDS é um surfactante, que é caracterizado por possuir duas regiões distintas na mesma molécula: uma região polar (hidrofílica) e outra região não polar (hidrofóbica); apresenta uma longa cadeia alquílica, praticamente insolúvel em água, ligada covalentemente a um grupo iônico, o sulfato de sódio. O SDS auxilia desde a solubilização das membranas celulares até a desnaturação de proteínas (RICKARD e GAHAN, 1983; NASIRI et al., 2005), o que sugere, pelos resultados obtidos neste trabalho, sua eficiência como agente inibidor da peroxidase, pela possível desnaturação das proteínas.

\subsection{Atividade enzimática da POD}

Estatisticamente, todos os inibidores reduziram a atividade da POD em relação ao controle, independentemente da concentração e do tempo de avaliação (Tabela 2). Para uma melhor discussão dos 

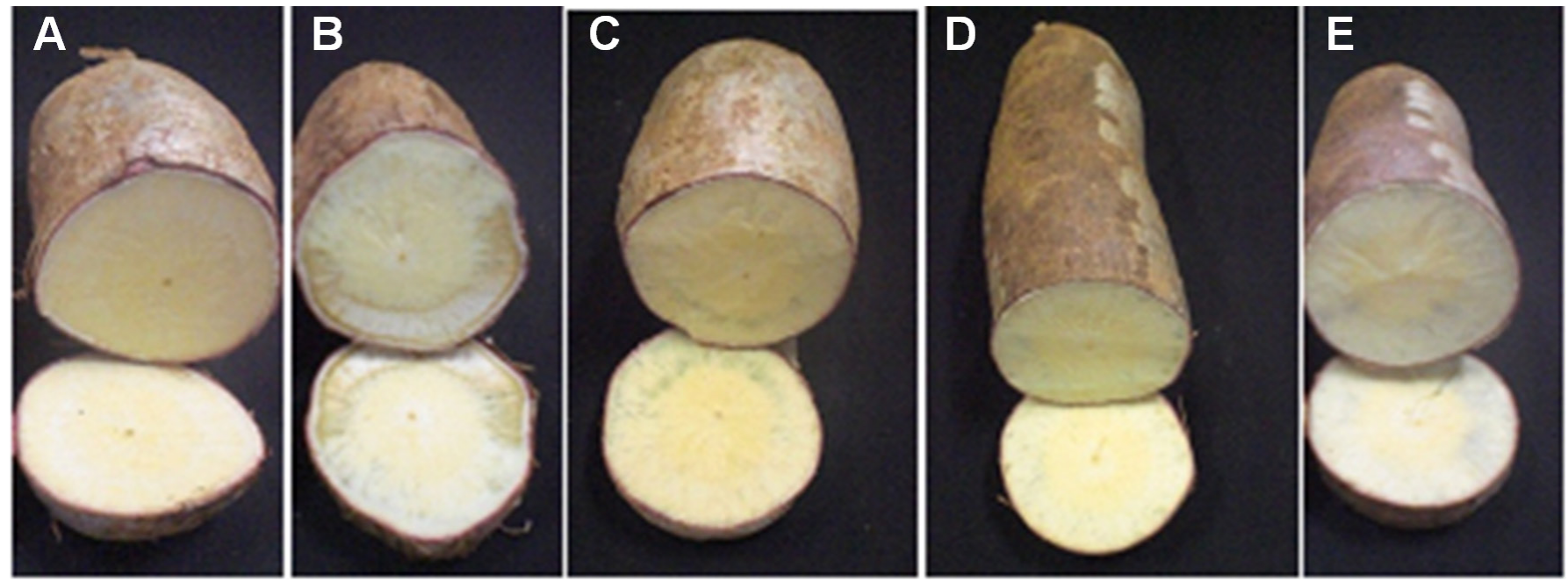

Figura 6. Aparência das raízes de mandioca após os tratamentos com SDS: (A) dia 2- concentrações 1, 5 e 10 mM, nota 1; (B) dia 4- concentração $1 \mathrm{mM}$, nota 7; (C) 5 mM, nota 5; (D) 10 mM, nota 3; (E) dia 6- concentração 1 mM, nota 7; (E) 5 mM e 10 mM, nota 5.

Tabela 2. Médias da atividade de peroxidase em raízes de mandioca in natura tratadas ou não com inibidores da POD nas concentrações: C1 mM, C5 mM e C10 mM, ao longo dos dias de armazenamento.

\begin{tabular}{|c|c|c|c|c|c|c|c|c|c|}
\hline \multirow{3}{*}{ Tratamentos } & \multicolumn{9}{|c|}{ Atividade da Peroxidade (UA min-1 $\mathrm{mg}^{-1}$ de proteína) } \\
\hline & \multicolumn{3}{|c|}{ Dia 2} & \multicolumn{3}{|c|}{ Dia 4} & \multicolumn{3}{|c|}{ Dia 6} \\
\hline & C1 & C 5 & C 10 & C1 & C 5 & C 10 & C1 & C 5 & C 10 \\
\hline Controle & $120,98^{a}$ & $120,98^{a}$ & $120,98^{a}$ & $212,691^{a}$ & $212,69^{a}$ & $212,69^{a}$ & $226,46^{a}$ & $226,46^{a}$ & $226,46^{a}$ \\
\hline Acido ascórbico & $3,20^{b}$ & $6,13^{b}$ & $3,89^{b}$ & $13,05^{b}$ & $24,1^{\mathrm{b}}$ & $22,98^{b}$ & $17,37^{\mathrm{b}}$ & $40,14^{b}$ & $134,02^{b}$ \\
\hline Bissulfito de Sódio & $3,59^{b}$ & $2,09^{b}$ & $1,65^{b}$ & $15,666^{b}$ & $7,64^{b}$ & $12,99^{b}$ & $114,84^{b}$ & $24,78^{b}$ & $43,51^{b}$ \\
\hline $\mathrm{Na}_{2}-\mathrm{EDTA}$ & $3,59^{b}$ & $4,40^{b}$ & $3,16^{b}$ & $24,793^{b}$ & $17,33^{b}$ & $6,66^{b}$ & $138,57^{b}$ & $27,36^{b}$ & $45,40^{b}$ \\
\hline L-cisteína & $4,34^{b}$ & $4,42^{b}$ & $3,28^{b}$ & $13,676^{b}$ & $7,07^{\mathrm{b}}$ & $16,5^{b}$ & $43,59^{b}$ & $46,95^{b}$ & $179,01^{a}$ \\
\hline SDS & $3,09^{b}$ & $3,85^{b}$ & $1,74^{\mathrm{b}}$ & $16,241^{b}$ & $16,07^{\mathrm{b}}$ & $12,79^{b}$ & $103,78^{b}$ & $60,73^{b}$ & $91,99^{b}$ \\
\hline CV (\%) & 11,9 & 12,7 & 12,1 & 4,7 & 8,0 & 4,9 & 17,4 & 7,4 & 27,9 \\
\hline
\end{tabular}

Médias seguidas pela mesma letra, na coluna, não diferem entre si pelo teste Ducan a 5 \% de probabilidade.

dados, consideraram-se como menores os valores de atividade da peroxidase, em todos os tratamentos, valores estes que foram, no mínimo, 20 vezes inferior ao controle em cada dia de armazenamento (Tabela 2).

Os inibidores de peroxidase no segundo dia do tratamento, com as concentrações 1, 5 e $10 \mathrm{mM}$, reduziram significativamente $(p<0,05)$ a atividade dessa enzima, quando comparados ao controle, com atividade de 120,98 UA $\mathrm{min}^{-1} \mathrm{mg}^{-1}$ de proteína (Tabela 2). Dentre os inibidores, verificou-se uma maior redução da atividade da POD em raízes de mandioca tratadas com bissulfito de sódio (1,65 UA min ${ }^{-1} \mathrm{mg}^{-1}$ de proteína) e SDS (1,74 UA min ${ }^{-1} \mathrm{mg}^{-1}$ de proteína) a $10 \mathrm{mM}$, em relação às concentrações de 1 e 5 mM.

No quarto dia de armazenamento, os menores valores de atividade da peroxidase foram 6,66, 7,07, 7,64 UA $\mathrm{min}^{-1} \mathrm{mg}^{-1}$ de proteína de raízes tratadas com $\mathrm{Na}_{2}$-EDTA a $10 \mathrm{mM}$, L-cisteína e bissulfito de sódio a $5 \mathrm{mM}$, respectivamente (Tabela 2 ). Inferindo-se ao resultado já apresentado na Tabela 1, esta menor atividade da peroxidase em raízes tratadas com $\mathrm{Na}_{2}$-EDTA, L-cisteína e bissulfito de sódio justifica o fato de as raízes apresentarem menor deterioração fisiológica, em virtude da eficiência do tratamento em reduzir a atividade de uma das enzimas, a POD, relacionada ao escurecimento enzimático.

O tratamento com bissulfito de sódio na concentração de $1 \mathrm{mM}$ promoveu atividade da POD de 15,67 UA min-1 $\mathrm{mg}^{-1}$ de proteína, no quarto dia. Comparando este resultado com a análise de qualidade, a esta concentração as raízes apresentaram impróprias para o consumo (Tabela 1 e 2). Assim, sugere-se que esse sal, aplicado em concentrações menores, não é eficiente para inibir a ação da peroxidase e reduzir o efeito do escurecimento em raízes de mandioca in natura.

Em estudos realizados com maçãs, usando-se a L-cisteína como inibidor da peroxidase verificou-se que $57 \%$ da atividade na variedade Kali foi inibida na concentração de 5 mM; 17 \% na variedade Devi e Kinnaur a $5 \mathrm{mM}$, e $21 \%$ da atividade na variedade Chocklaty a 2,5 mM (SINGH et al., 2010), resultado este semelhante ao encontrado neste trabalho, quando foi comparado 
Efeito de inibidores da peroxidase sobre a conservação de raízes de mandioca in natura

RAMOS, P. A. S. et al.

o tratamento com L-cisteína (5 mM) ao controle. Houve redução na atividade da peroxidase, acompanhada da redução do escurecimento enzimático, no quarto dia de armazenamento (Tabelas 1 e 2).

Em relação à atividade da POD no sexto dia de avaliação, houve diferença significativa entre os tratamentos em todas as concentrações, quando comparadas ao controle. Entretanto, a L-cisteína a $10 \mathrm{mM}$ teve atividade da POD (179,01 UA $\mathrm{min}^{-1} \mathrm{mg}^{-1}$ de proteína) estatisticamente igual ao controle $\left(226,46 \mathrm{UA} \mathrm{min}^{-1} \mathrm{mg}^{-1}\right.$ de proteína), em nível de 5 \% de significância (Tabela 2). As raízes tratadas com esse aminoácido tiveram nota 5 de escurecimento, enquanto que o controle foi classificado com nota 7 (Tabelas 1 e 2). Este resultado sugere que a L-cisteína deve agir inibindo outras enzimas que atuam no escurecimento.

Inibidores enzimáticos atuam por diferentes mecanismos (VOET et al., 2002): alguns são substâncias que se assemelham aos próprios substratos das enzimas, que reagem lentamente; outros inibidores interferem na atividade catalítica sem influenciar a ligação do substrato, e existem aqueles que atuam segundo os dois processos. A capacidade de diferentes compostos de inibir a POD depende da natureza e da concentração do inibidor.

Neste trabalho, utilizaram-se diferentes concentrações, as quais foram eficientes em reduzir significativamente a atividade da peroxidase em até seis dias. Entretanto, a L-cisteína a $10 \mathrm{mM}$ foi estatisticamente igual ao controle, o que não se explica pelas diferenças nas concentrações, mas pode estar relacionado com a disponibilidade de substratos fenólicos envolvidos na reação enzimática (COSTA et al., 2011).

\section{Conclusões}

Aos dois dias de armazenamento, $100 \%$ das raízes tiveram aparência ideal para comercialização, independentemente do tratamento.

Os tratamentos que proporcionaram melhor conservação pós-colheita foram o ácido ascórbico, o bissulfito de sódio e a L-cisteína, aumentando a vida de prateleira de dois para seis dias.

Os tratamentos com os inibidores ácido ascórbico, bissulfito de sódio, $\mathrm{Na}_{\mathbf{2}}$-EDTA e SDS reduziram a atividade da peroxidase até o sexto dia de armazenamento.

\section{Agradecimentos}

Ao CNPq, pela concessão da Bolsa de Pós-doutorado, e à FAPEMIG.

\section{Referências}

ARAÚJO, J. M. A. Química de Alimentos:Teoria e Prática. 2. ed. Viçosa:UFV, 1999. 416 p.
BRADFORD, M. M. A rapid and sensitive method for the quantitation of microgram quantities of protein utilizing the principle of protein-dye binding. Analytical Biochemistry, Athens, v. 72, p. 248-254, 1976. http://dx.doi.org/10.1016/00032697(76)90527-3

BORGES, M. F.; FUKUdA, W. M. G.; ROSSETI, A. G. Avaliação de variedades de mandioca para consumo humano. Pesquisa Agropecuária Brasileira, Brasília, v. 37, n. 11, p. 1559-1565, 2002. http://dx.doi.org/10.1590/S0100204X2002001100006

CANTOS, E.; TUDELA, J. A.; GIL, M. I.; ESPÍN, J. C. Phenolic compounds and related enzymes are not rate-limiting in browning development of fresh-cut potatoes. Journal of Agriculture and Food Chemistry, Washington, v. 50, p. 3015-3023, 2002. http:// dx.doi.org/10.1021/jf0116350

CEREDA, M. P.; VILPOUX, O. F. Conservação de raízes. In: CEREDA, M. P.; VILPOUX, O. F. Tecnologia, Usos e Potencialidades de Tuberosas Amiláceas Sul Americanas. 3. ed. São Paulo: Fundação Cargill, 2003. cap. 1, p. 13-29.

CHITARRA, A. B.; PRADO, M. E. T. Utilização de Atmosfera Modificada e Controlada em Frutos e Hortaliças. Lavras: UFLA/FAEPE, 2002. p. 13-15, 23-25, 40-42.

COSTA, A. C.; ANTUNES, P. L.; ROMBALD, C. V.; GULARTE, M. A. Controle do escurecimento enzimático e da firmeza de polpa em pêssegos minimamente Processados. Ciência Rural, Santa Maria, v. 41, n. 6, p. 1094-1101, 2011.

DUANGMAL, K.; APENTEN, R. K. O. A comparative study of polyphenoloxidases from taro (Colocasia esculenta) and potato (Solanum tuberosum var. Romano). Food Chemistry, West Yorkshire, v. 64, p. 351-359, 1999.

GOULART, P. B.; XAVIER, A.; DIAS, J. M. M. Efeito de antioxidantes no enraizamento de miniestacas de Clones de Eucalyptus Grandis X E. Urophylla. Revista Árvore, Viçosa, v. 34, n. 6, p. 961-972, 2010.

KATO, M. S. A. Armazenamento de Raízes Frescas de Mandioca (Manihot esculenta, Crantz) Após a Colheita. Belém: Embrapa-UEPAE de Belém, 1988. 30 p. (Documento, ก. 5).

MELO, A. A. M.; VILAS BOAS, E. V. B. Inibição do escurecimento enzimático de banana maçã minimamente processada. Ciência e Tecnologia de Alimentos, Campinas, v. 26, n. 1, p. 110-115, 2006. http://dx.doi.org/10.1590/S010120612006000100019

NASIRI, H.; FOROUZANDEH, M.; RASAEE, M. J.; RAHBARIZADEH, F. Modified salting-out method: high-yield, high-quality genomic DNA extraction from whole blood using laundry detergent. Journal of Clinical Laboratory Analysis, New York, v. 19, p. 229-232, 2005. http://dx.doi.org/10.1002/jcla.20083 
Efeito de inibidores da peroxidase sobre a conservação de raízes de mandioca in natura

RAMOS, P. A. S. et al.

NEVES, L. L. M. Envolvimento de Enzimas Oxidativas no Escurecimento do Quiabo [Abelmoschus esculentus (L.) Moench]. 2003. 72 f. Tese (Doutorado em Fisiologia Vegetal)Universidade Federal de Viçosa, Viçosa, 2003.

OLIVEIRA, M. A.; PANTAROTO, S. Efeito da sanitização e de agente antioxidante em raízes de mandioca minimamente processadas. Brazilian Journal Food Technology, Campinas, v. 6, n. 2, p. 339-344, 2003.

PINELI, L. L. O.; MORETTI, C. L.; ALMEIDA, G. C.; NASCIMENTO, A. B. G.; ONUKI, A. C. A. Associação de atmosfera modificada e antioxidantes reduz o escurecimento de batatas 'Ágata' minimamente processadas. Horticultura Brasileira, Brasília, v. 23, n. 4, p. 993-999, 2005. http://dx.doi.org/10.1590/S010205362005000400027

REIS, C. M. F.; VILAS BOAS, E. V. B.; BOARI, C. A.; PÍCCOLI, R. $\mathrm{H}$. Qualidade e vida de prateleira de banana prata minimamente processada. Ciência e Agrotecnologia, Lavras, v. 28, n. 3, p. 702-708, 2004.

RICKARD, J. E.; GAHAN, P. B. The development of occlusions in cassava (Manihot esculenta Crantz) root xylem vessels. Annals of Botany, s.I., n. 52, p. 811-821, 1983.

SAEG. Sistema para Análise Estatística. versão 9.1. Viçosa: Fundação Artur Bernardes, UFV, 2007.

SILLANPAA, M.; ORMA, M.; RAMO, J.; OIKAIR, A. The importance of ligand speciation in environmental research: a case study. The Science of the Total Environment, Finland, v. 267 , p. 23-31, 2001. http://dx.doi.org/10.1016/S00489697(00)00723-3

SINGH, J.; DUBEY, A.; DIWAKAR, S. K.; RAWAT, S. K.; BATRA, $\mathrm{N}$.; JOSHI, A. Biochemical characterization of peroxidases from the fruits of Mallus pumilus. International Research Journal of Biotechnology, India, v. 1, n. 4, p. 50-58, 2010.

SILVA, M. V.; ROSA, C. I. L. F.; VILAS BOAS, E. V. B. Conceitos e métodos de controle do escurecimento enzimático no processamento mínimo de frutas e hortaliças. Boletim do CEPPA, Curitiba, v. 27, n. 1, p. 83-96, 2009.

TOMÁS-BARBERÁN, F. A.; ESPÍN, J. C. Phenolic compounds and related enzymes as determinants of quality in fruits and vegetables. Journal of the Science of Food and Agriculture, Chicago, n. 81, p. 853-879, 2001.

VIEIRA, H. J.; FATIBELLO-FILHO, O. Determinação indireta de $\mathrm{N}$-acetil-L-cisteína por injeção em fluxo empregando Ce(IV) e ferroína. Quimica Nova, São Paulo, v. 28, n. 5, p. 797-800, 2005. http://dx.doi.org/10.1590/S0100-40422005000500012

VILAS BOAS, E. V. B. Qualidade de Alimentos Vegetais. Lavras: UFLA/FAEPE, 2002. p. 59.

VOET, D.; VOET, J. G.; PRATT, C. W. Enzimas. In: BASSO, L. A. (Ed.). Fundamentos de Bioquímica. Porto Alegre: Artmed, 2002. p. 279-349. 